\title{
Does Early Repair of Cleft Lip Helps to Reduce the Cleft Alveolar and Palatal Gap in Unilateral Complete Cleft Lip - Palate Patients?
}

Kazi Md Noor-ul Ferdous ${ }^{1^{*}}$

Md Mahfuzul Haq ${ }^{2}$

S M Mashfiqur Rahman ${ }^{3}$

Sabbir Karim ${ }^{3}$

Md Mahabubul Alam ${ }^{3}$

Kh Ahasanul Kabir ${ }^{3}$

Md Delwar Hossain ${ }^{3}$

Ayub $\mathrm{Ali}^{3}$

Md Moniruzzaman ${ }^{4}$

Khalid Mahmud ${ }^{3}$

M Rashadul Alam ${ }^{3}$

Gajendra Nath Mahato ${ }^{3}$

Tuhin Akter $^{3}$

'Division of Pediatric Surgery Dhaka Shishu (Children) Hospital Dhaka, Bangladesh.

${ }^{2}$ Department of Pediatric Surgery Rangpur Medical College \& Hospital Rangpur, Bangladesh.

${ }^{3}$ Department of Pediatric Surgery Bangladesh Institute of Child Health Dhaka Shishu (Children) Hospital Dhaka, Bangladesh.

\begin{abstract}
Backgroud: Timing of surgery in the patients with cleft lip palate is an important factor of prognosis. Delaying in surgical repair of cleft lip and palate patient may lead to difficulty. It may causes wide, extensive and difficult dissection. There are always chances of wound infection, wound dehiscence, complete wound disruption, fistula formation, even there is also chance of maxillary hypoplasia and failure to articulate lifelong. The purpose of this study to observe the effects of cleft lip repair in early age on cleft alveolar and cleft palatal gap thus helps during cleft hard palate repair in patients with unilateral complete cleft lip and palate (UCLP). Methods: A retrospective study was done from January 2008 to July 2013. Patients with unilateral complete cleft lip and palate included in this study, who under went cleft lip at first admission and then and after 3 months of cleft palate was repaired. Patients with previous cleft lip-palate surgery were excluded. The gaps of cleft alveolus and posterior border of the cleft hard palate were recorded during 1st and 2nd operations. Age, gender, side of the cleft, associated anomalies, family history of cleft, cleft alveolar and cleft palatal gap noted, postoperative complications were also recorded. All the data were Results: A total of 63 patients included in this study. Age ranged from 4 months to 8 years. 38 patients were male and 25 were female. Right side was involved in 20 and 43 patients involved in left side. Eight patients had positive family history. Nine had associated congenital anomalies. Cleft alveolar and palatal gap reduced more in the patients who were below the age of 18 months. Postoperative complications were mild respiratory distress, notching of vermilion border developed oronasal fistula. Conclusion: In unilateral complete cleft lip palate patient, early cleft lip repair results, reduction of gaps of alveolar cleft and that of hard palate remarkably, especially in the patients who came for cleft lip surgery in appropriate time.
\end{abstract}

Key words: Unilateral Complete Cleft Lip-Palate; Cleft alveolar gap; Cleft palatal gap.

\section{INTRODUCTION}

Every year more than 5000 patients with cleft lip and palate are born ${ }^{1}$. It is the third most common congenital anomalies in our country. The incidence of cleft lip or/and cleft palate in Bangladesh is 3.9 per 1000 live births ${ }^{2}$. Incidences of cleft lip-palate and other multifactorial congenital malformation are increasing day by day due to environmental pollution, misuse of drugs by pregnant women, radiation hazards etc ${ }^{3}$. In our country most of the cleft patients come to the doctor only when their parents are aware or when the child had some problem like repeated respiratory tract infection, feeding difficulty, various social problem. Many of these patients present with abnormal teeth eruption, permanent articular problems, repeated ear infection, may have deafness etc. For these regions, we get patients of varying ages ${ }^{1}$.

The primary goal of treatment focuses on anatomical closure of the defects in order to improve feeding and speech development, without significant impending maxillary growth or increasing fistula incidence. The timing of surgery and the technique to obtain these results remain controversial ${ }^{4}$.

\section{Dr. Kazi Md Noor-ul Ferdous Registrar \\ Department of Pediatric Surgery \\ Dhaka Shishu (Children) Hospital \\ Sher-E-Bangla Nagar \\ Dhaka, Bangladesh. \\ Mobile: +8801711322487 \\ E-mail:kmnferdous@gmail.com}


Though some centers the cleft lip is repaired before mother and newborn go home from hospital. Most of the surgeons prefer to wait for "Rule of 10 ", that is $10 \mathrm{lb}$ weight, $10 \mathrm{gm} \mathrm{Hb} \%, 10$ wks, that is around 3 months of age for repair of cleft lip. Cleft palate should be closed within 9-18 months of age before development of $\operatorname{speech}^{5}$. The incidence of unilateral complete cleft lip palate is more than bilateral cleft ${ }^{6}$. Compare with cleft lip repair, palatoplasty needs extensive dissection, takes more time for operation and more chances of oronasal fistula formation and if cleft palate repair is done earlier there may be mid facial growth disturbance ${ }^{7-8}$.

Even after repair, there may be chances of wound disruption, oronasal fistula formation. Some parents prefer cleft lip repair first irrespective of the age of the child only for aesthetic region and do not come again for cleft palate or oronasal fistula closure due to poverty, transport problem, lack of knowledge $e^{3,9}$. Late repair of this defect is complicated by high fistula formation and which may persist for an extended period of time $^{8}$. Early complete closure of the cleft allowed for earlier intelligibility of speech compound to the staged later closure ${ }^{10}$.

\section{MATARIALS \& METHODS}

A retrospective study was carried out in the Department of Pediatric Surgery, Dhaka Shishu (Children) Hospital; Dhaka, during the period of January 2008 to July 2013. We analyzed the data of the patients with unilateral complete cleft lip and cleft palate from 3 months to 10 years from hospital records. The patients with previous surgery for cleft lip-palate and unilateral cleft with other deformities of face were excluded. Records included age, gender, side of cleft, family history of cleft, associated anomalies, clinical examination, surgical procedures and follow up results. The following investigations were commonly performed: Hemoglobin percentage, Bleeding time, clotting time, Blood group. Cleft lip was repaired by modified Millard's procedure and then after 12 to 13 weeks cleft palate was repaired by Veau-Wardill-Kilner technique. Cleft alveolar and cleft palatal gap (at posterior border of heard palate) were measured after intubation, before starting the operation. After 4 to 6 hours of the operation plain water was given orally. All the patients were discharge on $2^{\text {nd }}$ or $3^{\text {rd }}$ post operative day, with the advice to be on tropical and oral antibiotics, analgesia, liquid diet (at least for 2 weeks for palate repair) followed semisolid diet with spoon for and should take plenty of water after each feeding. They were also advised to come for follow up (and for lip stitch remove) on $5^{\text {th }}$ to $7^{\text {th }}$ day and on 4-6 weeks after operation. On immediate post operative and subsequent follow up any bleeding, respiratory distress, flap necrosis, wound disruption, wound dehiscence, wound infection, fistula formation were noticed. Then all the patients advised to come on $7^{\text {th }}$ post operative day, then after 1 month, 3 month, 6 months, 12 months, 18 months and onwards.

\section{RESULTS}

A total of 63 unilateral complete cleft lip and palate patients were studied. The age of the patients in this study group ranged from 4 months to 8 years. Mean \pm SD was $26.4 \pm 23.7$ months and median was 13.9 months. Maximum patients were $(n=25)$ within 6 months to 12 months. A total of 38 patients were male $(60 \%)$ and 25 were female $(40 \%)$ ratio in whole study group was $\mathrm{M}: \mathrm{F}=1.5$ : 1 . Among 63 patients, right side was involved in $20(32 \%)$ patients and $43(68 \%)$ patients involved in left side.

Only $8(13 \%)$ patients had positive family history of cleft lip. Mothers of two patients had isolated cleft palate only, and other two's had paternal or maternal relatives with a history of cleft lip \pm palate.

Among the study group ( $n=63$ ) four patients associated with ASD, two had PDA, one had VSD, one had external ear anomalies and another one had bilateral talipes equino varus.

All 63 patients were divided in two groups according to their age. In first group (3-18 months) there were 40 patients and in second group ( $>18$ months) there were 23 patients. Cleft alveolar gap and cleft palatal gap at the posterior border were measured after the patients were intubated. [Table-I, II].

Table I : Cleft alveolar gap $(\mathrm{N}=63)$

\begin{tabular}{lcccc} 
Age (month) & \multicolumn{2}{l}{$\begin{array}{l}\text { Gap before cleft lip repair }(\mathrm{mm}) \\
\end{array}$} & \multicolumn{2}{l}{ Total gap reduced $(\mathrm{mm})$} \\
& Up to 7.50 & $>7.50$ & Up to 5.00 & $>5.00$ \\
$3-18(\mathrm{~N}=40)$ & $22(55 \%)$ & $18(45 \%)$ & $28(70 \%)$ & $12(30 \%)$ \\
$>18(\mathrm{~N}=23)$ & $15(65 \%)$ & $8(35 \%)$ & $22(96 \%)$ & $1(4 \%)$ \\
Mean \pm SD & $7.28 \pm 2.78$ & $4.36 \pm 1.44$ \\
Median & 7.20 & 4.28 \\
\hline
\end{tabular}

Table II : Cleft palatal gap $(\mathrm{N}=63)$

\begin{tabular}{lcclc} 
Age (month) & \multicolumn{2}{l}{ Gap before cleft lip repair $(\mathrm{mm})$} & \multicolumn{2}{l}{ Total gap reduced $(\mathrm{mm})$} \\
& Up to 12.00 $>12.00$ & Up to 3.50 & $>3.50$ \\
$3-18(\mathrm{~N}=40)$ & $18(45 \%)$ & $22(55 \%)$ & $32(80 \%)$ & $8(20 \%)$ \\
$>18(\mathrm{~N}=23)$ & $15(65 \%)$ & $8(35 \%)$ & $23(100 \%)$ & 0 \\
Mean $\pm \mathrm{SD}$ & $12.12 \pm 2.68$ & $2.04 \pm 0.59$ \\
Median & \multicolumn{2}{c}{12.00} & \multicolumn{2}{c}{2.00}
\end{tabular}

Cleft alveolar gap reduced more than $5 \mathrm{~mm}$ in 13 patients and only one of them was above 18 months of age group. Mean cleft palatal gap reduced $2.1 \mathrm{~mm}$. But cleft palatal gap of only one patient reduced more than $3.5 \mathrm{~mm}$, whom age was 19 months.

No immediate post operative complication observed after cleft lip operation. On $5-7^{\text {th }}$ postoperative day (during lip stitches removal) in $5(8 \%)$ patients were found notching of vermilion border. Seven patients (11\%) developed oronasal fistula, whom were above 2 years old.

Table III : Post operative complications in $1^{\text {st }}$ and $2^{\text {nd }}$ operation between two groups

\begin{tabular}{lllll} 
Complications & \multicolumn{2}{l}{$\begin{array}{l}\text { Immediate Post Operation } \\
\text { After cleft lip }\end{array}$} & $\begin{array}{l}\text { After } \\
\text { Oth }\end{array} 7^{\text {th }}$ POD \\
repair & palatoplasty & $\begin{array}{l}\text { After cleft } \\
\text { lip repair }\end{array}$ & $\begin{array}{l}\text { After } \\
\text { palatoplasty }\end{array}$ \\
Mild Bleeding & - & - & - & - \\
Mild Respiratory difficulty & - & $16(25 \%)$ & - & - \\
$\begin{array}{l}\text { Vermilion border notching } \\
\text { Oronasal fistula. }\end{array}$ & - & - & $5(6 \%)$ & \\
\hline
\end{tabular}

Mean follow up time 14.4 months $(\mathrm{SD} \pm 1.23)$. Follow up range was 12 months to 29 months. No patients found maxillary growth disturbance. 


\section{DISCUSSION}

Cleft lip and palate is the third most common congenital deformities in Bangladesh, which can be corrected surgically ${ }^{2,11}$. Most of the cleft patients come to the doctor only when their parents are aware or when the child has some problem such as repeated respiratory tract infection, social problem, etc. Thus we get patients of varying ages. These patients presents with permanent articular problems, abnormal teeth eruption, deafness, etc. Even after surgery, they may present with wound disruption or recurrent oronasal fistula formation. Some parents prefer cleft lip repair first irrespective of the age of the child, only for esthetic reasons, and do not come again for cleft palate or oronasal fistula closure ${ }^{3}$. Palatoplasty often needs extensive dissection, specially if the age of the patients is more and there may be more chances of oronasal fistula formation, which is very difficult to repair, and may cause mid-facial growth disturbance ${ }^{7,12}$.

This retrospective study was done to evaluate the patients of unilateral complete cleft lip - palate and to observe the result of surgery. It was specially, whether the cleft lip repair procedure can reduce the gaps of cleft palate and alveolus and the incidence of oronasal fistula formation.

In most studies on cleft lip and cleft palate surgery the age of the patients was 3-7 months, Our study differ from those, and we got the patients with wide age range ${ }^{7-8,13}$. This was probably due to the parents' educational, socio-economic and cultural influences regarding whether these children would be brought to the hospital or not ${ }^{11}$. Some time cleft babies brought to just after birth, and advised how to deal with and to come at time for surgery. But, we could not do surgery at time, as patients were malnourished. The male female ratio $(1.5: 1)$ in our study group was similar (1.5:1 to $2.1: 1)$ with other ${ }^{3,7,14}$. Side of cleft is also similar to the literatures where showed more cleft involvement in the left side than the right. We found right side involved $32 \%$ and in the left side $68 \% \%^{3,7,11}$.

A study was done in 1998 on cleft lip with or without palate $(\mathrm{n}=60)$ in Dhaka Shishu hospital congenital heart disease was in $1.6 \%$, and other anomalies were congenital bands in limb (3.3\%), Polydactyle (3.3\%), Apart's syndrome $(3.3 \%)^{11}$. We found nine patients with others associated congenital anomalies like ASD,VSD, PDA, congenital heart disease, external ear anomalies and talipes equino varus.

Only $8(13 \%)$ patients had positive family history of cleft lip. Mother of two of them had isolated cleft palate only. Sarwar showed family history was $15 \%$ positive in his study on cleft lip-palate patients ${ }^{11}$.
Samuel et al said, family history has significantly increased of cleft lip and palate among the relatives of cleft lip and palate parents but isolated cleft lip and palate occur frequently in general population ${ }^{15}$. Fraser et al believed that isolated cleft palate is a genetic entity distinct from unilateral cleft lip with or without cleft palate ${ }^{16}$.

We found after cleft lip repair, mean cleft alveolar gap reduced by $4.36 \mathrm{~mm}( \pm 1.44 \mathrm{SD})$. The cleft alveolar gap was reduced by more than $5 \mathrm{~mm}$ in thirteen patients, but, only one of whom was 19 months of age. Similarly, after cleft lip repaired we found mean cleft palatal gap reduced by $2.04 \mathrm{~mm}(\mathrm{SD} \pm 0.59)$.

The cleft palatal gap was reduced more than $3.5 \mathrm{~mm}$ in $8(20 \%)$ patients who were under 18 months of age, none of above 18 months of age.

In some recent studies on unilateral complete cleft lip- palate patients, in control group they only repaired cleft lip and during palatoplasty they found cleft alveolar and platal gap reduced significantly but the reduction was highly significant when they used vomer flap to repair hard palate during simultaneous repair of cleft lip ${ }^{3-4,7}$.

After cleft lip repair, no immediate postoperative complication was observed in any patient. But, after palatoplasty fourteen patients needed blood transfusion after the second operation, due to extensive palatal dissection, and sixteen patients were observed with mild respiratory difficulty, probably due to reduction of oral cavity space and less space for tongue. We found five patients were developed vermilion line notching on the 5 th -7 th postoperative day of the lip repaired. Those occurred in our surgery and after developing surgical skill, no patients developed vermilion line notching. On the 5 th $-7^{\text {th }}$ postoperative day following the palatoplasty, seven (11\%) patients developed anterior oronasal fistula, the age of whom was above 2 years and the cleft palatal gap was wide. In other studies, fistula rates were higher. Some authors advocate using vomar flap to reduce oronasal fistula rate re, $^{3,7,11,17-19}$.

\section{CONCLUSION}

In unilateral cleft lip palate patients, repair of cleft lip results, reduction of gaps of alveolar cleft and that of hard palate were reduced remarkably, especially in the patients who came for cleft lip surgery in appropriate time. So, it is better to repair cleft lip in appropriate age to easy and effective repair of cleft palate.

\section{DISCLOSURE}

All the authors declared no competing interest. 


\section{REFERENCES}

1. Ferdous KMN, Salek AJM, Islam MK, Das BK, Khan AR, Karim MK Repair of cleft lip and simultaneous repair of cleft hard palate with vomer flap in unilateral complete cleft lip and palate: a comparative study, Pediatr Surg Int. 2010; 26(10) : 995-1000.

2. Rasul CH, Hassan MA, Rahman MS Congenital anomalies in the Newborn. J coll Physician Surg. 1998; 16(1):11-12.

3. Arvier, JF, Molla, MR, Fitzpatrick, B, Shaheed, SMI, Lanza, K, 'Trans-antral temporalis transfer for the repair of the cleft palates', Australian Dental Journal. 1997;42(5):307-314.

4. Jong de J P (2013) Early hard palate closure using a vomer flap in unilateral cleft lip and palate: effects on cleft width; Clin oral Invest. DOI10.1007/s00784-013-1091-3, online-29 August2013.

5. Lee KJ Comprehensive surgical atlases in otolaryngology and head and neck surgery. Grune \& Stratton, Inc., New York. 1983;101-262.

6. Agrawal K. Cleft palate repair and variations. Indian J Plast Surg. 2009; 42(Suppl):102-109.

7. Li W, Zheng Q, We S. Simultaneous repair of cleft lip and closure of hard palate with vomer flaps in patients With unilateral complete cleft lip and palate. West China J Stomatol. 2003; 21(1): 34-35 \& 47.

8. Lehman JA, Douglus BK, Ho WC, Husami TW. One stage closure of entire primary palate. Plast Reconstr Surg. 1990; 86(4): 675-681.

9. Mey A. Midfacial morphology in children with unilateral cleft lip and palate treated by different surgical protocols. Int J Oral Maxillofac Surg. 2002; 31:13-22.

10. De Mey A, Swennen G, Malevez C. Long-term follow-up of UCLP at the Reine Fabiola Children's Hospital. B-ENT. 2006;2(4):44-50.

11. Sarwar H (1998) Cleft palate in children: surgery and outcome. MS thesis, Bangladesh Institute Child Health, University of Dhaka.

12. Butow KW. Primary surgical repair of the palate. In: Brian W, Cochran MFA (eds) Treatment of facial cleft deformities: an illustrated guide. Ishiyaku Euro Amirica Inc., St. Louis. 1995; 21-32.

13. Kirschner RE, Randal IP, Jawad AF. Cleft palate repair at 3 to 7 months of age. Plast Reconstr Surg. 2000; 105:2127-2132.

14. Chris DJ, Donald JB, Patrick FM. A comparison of craniofacial from in Northern Irish children with unilateral cleft lip and palate treated with different primary surgical techniques. Cleft Palate Craniofac J. 2004; 4(1):42-46

15. Samuel, NM, Philip, KTC. ‘Unilateral Cheiloplasty’, in Mathes, JS (ed.), Plastic Surg. (Pediatric Plastic Surgery). $2^{\text {nd }}$ edn. Elsevier Inc, Philadelphia, PA. 2006; 4:165-215.

16. Fraser, FC. 'The Willam Allan Memorial Award Address: evoluation of a palatable Multifactorial threshold model', American journal of Human Genetics. 1980; 32:796-813.

17. Khundkar SH, Kalam MA. Cleft palate repair: a modified procedure. J Bangladesh Coll Phys Surg. 1998; 16(1):4-10.

18. Cohen SR, Kalinowski J, LaRossa D, Randell P. Cleft palate fistula: a multivariant statistical analysis of prevalence, etiology and surgical management. Plast Reconstr Surg. 1991; 87:1041-1047.

19. Diah E, Lo LJ, Yun C, Wang R. Cleft oronasal fistula: a review of treatment results and a surgical management algorithm proposal. Chang Gung Med J. 2007; 30(6):529-537. 